\title{
Is Multiparity in Adolescent Pregnancies Associated with Adverse Outcome?
}

\author{
Mert TURGAL ${ }^{1}$, Banu SEVEN ${ }^{2}$, Bilal ICER ${ }^{2}$, Ismail Burak GULTEKIN ${ }^{2}$, Tuncay KUCUKOZKAN ${ }^{2}$
}

Ankara, Turkey

\section{ABSTRACT}

OBJECTIVE: Aim of this study was to compare the maternal and neonatal outcomes between adolescent multiparas and adults.

STUDY DESIGN: This retrospective cohort study included over 11 years and singleton multiparous pregnancies from women less than 29 years admitted for delivery after $22^{\text {nd }}$ gestational weeks in tertiary educational hospital. All of patients were divided into two groups as adolescent multipara (under 18 years) and control (19-29 years). Pregnancy outcome and perinatal complications were evaluated. Mann-Whitney U-test, Independent sample t test, Pearson Chi-square test and Fisher Exact test were used for statistical analyses.

RESULTS: Gestational week at delivery was significantly lower in adolescent multipara group (38.37 \pm $2.17)$ than control group $(38.79 \pm 1.684)(p=0.014)$. Preterm birth rate $(12.6 \%)$ and postpartum hemorrhage $(5.7 \%)$ were higher in the adolescent multipara group than in controls as to be statistically significant. The cesarean delivery rate and other pregnancy complications such as diabetes mellitus, preeclampsia, intrauterine growth restriction, oligohydramnios, polyhydramnios, and placental abruption were similar with controls.

CONCLUSION: In conclusion, adolescent multipara pregnancies were associated with higher risks of adverse pregnancy outcomes, in particular preterm birth, lower birthweight and postpartum hemorrhage.

Keywords: Adolescent pregnancy, Caesarean section, Low birthweight, Perinatal mortality,

Preterm birth

Gynecol Obstet Reprod Med 2018;24(3):124-128

\section{Introduction}

Adolescent pregnancy (AP) has virtually higher maternal and perinatal morbidity and mortality than adult pregnancy. Most of these pregnancies are seen in developing countries. The World Health Organization reported that about 16 million girls which are aged 15 to 19 years and two million girls under the age of 15 give birth every year. Ninety-five percent of APs that

${ }^{I}$ University of Health Sciences Etlik Zubeyde Hanım Women's Health Teaching and Research Hospital Department of Perinatology, Ankara

${ }^{2}$ University of Health Sciences Dr. Sami Ulus Maternity and Children's Research and Educational Hospital, Department of Obstetrics and Gynecology, Ankara

Address of Correspondence: Mert Turgal

University of Health Sciences Etlik

Zubeyde Hanum Hospital, 06010

Ankara, Turkey

mertturgal@gmail.com

Submitted for Publication: 05.01.2017

Accepted for Publication: $\quad 16.03 .2018$

\begin{tabular}{|c|c|}
\hline & Access this article online \\
\hline $\begin{array}{c}\text { Quick Response Code: } \\
\text { Q }\end{array}$ & $\begin{array}{c}\text { Website: www.gorm.com.tr } \\
\text { e mail: info@gorm.com.tr }\end{array}$ \\
\cline { 2 - 3 } & DOI:10.21613/GORM.2018.705 \\
\hline
\end{tabular}

How to cite this article: Turgal M. Seven B. Icer B. Gultekin IB. Kucukozkan T. Is Multiparity in Adolescent Pregnancies Associated with Adverse Outcome? Gynecol Obstet Reprod Med 2018;24(3):124-128 occur each year are in low- and middle-income countries (1). Adolescent pregnancies are associated with adverse pregnancy outcomes. Previous studies about adolescent pregnancy have reported several complications such as low birth weight, stillbirth, preterm delivery, maternal anemia, postpartum depression, eclampsia, maternal death and postnatal death (2-6).

Previous studies shown that multiparity in adult population seems to be also correlated with a lesser risk than primiparity, except the greater incidence of macrosomia among grand multiparas $(7,8)$.

Several studies have evaluated the pregnancy outcomes and perinatal complications of first pregnancies in adolescents. However, there were few studies about the pregnancy outcomes of adolescent multipara. On the other hand, adolescent pregnancies are gradually increasing day by day in our country, especially in low income population group. Our hospital has intensively served this group. Hence, in this study, we aimed to compare pregnancy outcome and perinatal complications between adolescent multipara and adult multipara.

\section{Material and Method}

This was a retrospective cohort study over 11 years. All singleton multiparous pregnancies from women less than 29 years admitted for delivery after $22^{\text {nd }}$ gestational weeks to our 
hospital from 1 January 2005 to 30 November June 2015 were eligible for the analysis. This variable was categorized by two groups: adolescent multipara (under 18 years) and control (1929 years).

Data collection for the obstetric database from which the adolescent multipara and controls were drawn was under full ethical approval of the Local Ethics Committee (approval number: 2015-1009).

We collected 87 adolescent multiparous pregnancies attending our hospital from 2005 to 2015 . Clinical characteristics including maternal age, gravida, parity, labor interval for last pregnancy, pregnancy outcome, and perinatal complications were evaluated. Labor characteristics and perinatal outcomes including gestational age, birthweight, and 1 st and $5^{\text {th }}$ minute Apgar scores were also assessed. Adequate pregnancy follow up was defined more than 7 visits at antenatal period.

\section{Control group}

Data regarding 1280 adult (19-29 years) multiparous women were matched from an obstetric database of women attending our hospital for routine clinical care in the period 2005-2015. Matching criteria included gravida, parity, and labor interval for the last two pregnancies (months).
Descriptive statistics were used to describe and compare the baseline characteristics of the patient groups. Continuous variables were compared using Student's t test and categorical variables were compared using the chi-square test. A p-value of $<0.05$ was accepted as statistically significant. All statistical analyses were performed using SPSS v.20.0 for Windows (SPSS, Inc., Chicago, IL).

\section{Results}

Between January 2005 and November 2015, 20,181 women gave birth in our obstetrics department. Mean maternal age at delivery among the adolescent multipara and controls were $17.70 \pm 0.59$ and $24.53 \pm 3.82$ years, respectively $(p<0.001)$. There were no significant statistical differences in terms of baseline characteristics of the study groups (except age) using the match process. Table 1 illustrates the comparison of these characteristics between two groups.

Table 2 shows the pregnancy outcome of the groups. No statistically significant difference was found between adolescent multipara and control groups in terms of adequate antenatal follow up. When compared live birth rates between both groups, there was no significant difference. Gestational week at

Table 1: Baseline characteristics of the study groups, who adolescent multipara $(n=87)$ or controls $(n=384)$.

\begin{tabular}{lccc}
\hline & $\begin{array}{c}\text { Adolescent multipara } \\
\text { (n: } 87)\end{array}$ & $\begin{array}{c}\text { Control group } \\
\text { (n: 384) }\end{array}$ & $\begin{array}{c}p \\
\text { value }\end{array}$ \\
\hline Age (years) & $17.7 \pm 0.6$ & $24.5 \pm 3.8$ & $<0.01^{*}$ \\
Gravida (min-max) & $2(2-4)$ & $2(2-6)$ & $0.41^{*}$ \\
Parity (min-max) & $1(1-3)$ & $1(1-5)$ & $0.07^{*}$ \\
Labor interval (months) & $17.5 \pm 4.8$ & $17.4 \pm 4.3$ & $0.89^{*}$ \\
\hline
\end{tabular}

*Mann-Whitney U-test.

Data are expressed as mean $\pm S D$ or median (minimum-maximum).

Table 2: Pregnancy outcomes in both groups.

\begin{tabular}{|c|c|c|c|}
\hline & $\begin{array}{l}\text { Adolescent multipara } \\
\qquad(\mathrm{n}: 87)\end{array}$ & $\begin{array}{l}\text { Control group } \\
\quad(n: 384)\end{array}$ & $p$ value \\
\hline Gestational age at delivery (weeks) & $38.4 \pm 2.2$ & $38.8 \pm 1.7$ & $0.01^{*}$ \\
\hline Adequate antenatal follow-up (\%) & $60.9 \%$ & $62.0 \%$ & $0.85^{\neq}$ \\
\hline Birth weight (gr) & $2974 \pm 542$ & $3184 \pm 504$ & $0.01^{\dagger}$ \\
\hline Live birth rate $(\%)$ & $100 \%$ & $99.5 \%$ & $0.50^{\neq}$ \\
\hline Delivery week <32 & $2.3 \%$ & $1.6 \%$ & $0.63^{\neq}$ \\
\hline Delivery week <34 & $4.5 \%$ & $2.6 \%$ & $0.32^{\neq}$ \\
\hline Delivery week <37 & $12.6 \%$ & $6.0 \%$ & $0.03^{\neq}$ \\
\hline Cesarean section rate $(\%)$ & $41.4 \%(36 / 87)$ & $50.5 \%(195 / 384)$ & $0.12 \neq$ \\
\hline Episiotomy (\%) & $66.7 \%(34 / 51)$ & $62.1 \%(118 / 189)$ & $0.55^{\neq}$ \\
\hline Instrumental vaginal delivery & $0 \%(0 / 51)$ & $2.1 \%(4 / 189)$ & $0.58^{\neq}$ \\
\hline Apgar score $1^{\text {st }} \min (\min -\max )$ & $8(4-10)$ & $8(1-10)$ & $<0.00^{\dagger}$ \\
\hline Apgar score $5^{\text {th }} \min (\min -\max )$ & $9(5-10)$ & $9(4-10)$ & $0.01^{\dagger}$ \\
\hline Low Apgar score $\left.(<7) 5^{\text {th }} \min ((\mathrm{n}) \%)\right)$ & $(6 / 87) 6.8 \%$ & (13/384) $3.3 \%$ & 0.13 \\
\hline Postpartum hemoglobin (gr/dL) & $11.1 \pm 1.3$ & $11.2 \pm 1.5$ & $0.78^{\dagger}$ \\
\hline
\end{tabular}

Data are expressed as mean $\pm S D$ or median (minimum-maximum).

${ }^{*}$ Mann-Whitney U-test. $t$ : Independent sample $t$ test. $\neq$ : Pearson Chi-square test or Fisher Exact test. 
delivery was significantly lower in adolescent multipara group than control group $(p=0.014)$. Birth weight was lower in adolescent multipara than controls $(2974.1 \pm 542.0$ gr vs $3184.5 \pm$ 504.9 gr, $\mathrm{p}=0.001)$. Likewise, both Apgar score $1^{\text {st }}$ minute and $5^{\text {th }}$ minute showed a statistically significant difference between the two groups, $p<0.001$ and $\mathrm{p}=0.005$, respectively. Cesarean section rate and postpartum hemoglobin levels were similar.

Analysis of perinatal complications is given table 3 . Preterm birth rates were significantly higher in adolescent multipara group than controls $(12.6 \%$ vs $6.0 \%, \mathrm{p}=0.030)$, but delivery at $<32^{\text {nd }}$ gestational weeks were similar in both groups $(\mathrm{p}=0.630)$. Diabetes mellitus, preeclampsia, intrauterine growth restriction, oligohydramnios, polyhydramnios, placental abruption were similar between the adolescent multipara and control group. However, postpartum hemorrhage rate was significantly higher adolescent multipara than control group, $5.7 \%$ and $1.8 \%$, respectively $(\mathrm{p}=0.036)$. All of the patients were managed with medical approach. There was no surgical control of bleeding or postpartum hysterectomy cases.

\section{Discussion}

Adolescent pregnancy and its adverse perinatal outcomes are a global health care problem. Several factors including substance abuse, alcohol consumption, low income, and socioeconomic problems may associate with adverse perinatal outcomes. Additionally, younger age seems to be most important factor for poor pregnancy outcome (9). On the other hand, when compared with low multiparity (1-3 pregnancies), mothers and babies of nulliparity and grand multipara (4 or higher previous pregnancies) have higher risk for perinatal complications in adult population (10). However, there are not adequate analyses for adolescent multipara pregnancies in current literature.

In this study, we conclude that gestational week at delivery was significantly lower in adolescent multipara group than control group, $38.4 \pm 2.2$ weeks and $38.8 \pm 1.7$ weeks, respectively ( $\mathrm{p}=0.014)$. Additionally, we detected statistically higher preterm birth rates ( $<37$ weeks) in adolescent multipara group than controls $(12.6 \%$ vs $6.0 \%, \mathrm{p}=0.03)$. Our results are consistent with literature. In a retrospective cohort study, Iacobelli et al compared singleton adolescent $(<18$ years) and adult pregnancies (18-29 years) and found that adolescent pregnancy had higher preterm birth rate compared adult pregnancies $($ Odds ratio $=1.27(1.10-1.47), p=0.0008)(11)$. Similarly, in an observational study, preterm birth rates were higher in teenager $(11.6 \%)$ than controls $(8.5 \%)$ but difference was not statistically significant (12). The marked high incidence of preterm birth among adolescents in our study could not be explained by the poor antenatal care because achieve to adequate antenatal follow-up was similar in both study groups. The higher rate may be associated with the late recognition of pregnancy complications and nutritional problems.

We found statistically insignificant lower cesarean section rate in adolescent multipara. The decreased cesarean section rate in adolescent multipara mothers is consistent with results of several reports and meta-analyses $(3,9,11,13-15)$. However, in this study, the decreased rate of cesarean delivery was not associated with a higher rate of episiotomy or instrumental vaginal delivery ( $p=0.548$ and 0.581 , respectively). These findings have already been evaluated for adolescent primiparous pregnancies $(11,14,16)$, but never in adolescent multipara mothers. The studies by de Vienne et al. and Torvie et al. reported lower risks for operative vaginal delivery, whereas that by Konje et al. reported a 2 -fold. Conversely, we did not detect finding in favor of adolescent multipara in our study.

To our knowledge, few studies have been reported about perinatal outcomes in adolescent multipara. A recent study, Timur et al. found that the second pregnancies of adolescents were associated with fewer adverse perinatal outcomes than their first pregnancies. They described that neonatal intensive care unit admission rate, preeclampsia rate, low neonatal birth weight rate, and 5-minute Apgar scores $<7$ were significantly higher in the first than in the second pregnancy (17). In another retrospective cohort study included 110,233 pregnancies

Table 3: Analysis of perinatal complications.

\begin{tabular}{|c|c|c|c|c|}
\hline & $\begin{array}{l}\text { Adolescent multipara } \\
\text { (n: 87) }\end{array}$ & $\begin{array}{l}\text { Control group } \\
\text { (n: } 384)\end{array}$ & $\mathrm{X}^{2}$ statistic & $p$ value \\
\hline Preterm birth <32 & $2(2.3 \%)$ & $62(1.6 \%)$ & 0.230 & $0.63^{\neq}$ \\
\hline Preterm birth <37 & $11(12.6 \%)$ & $23(6.0 \%)$ & 4.869 & $0.03 \neq$ \\
\hline Diabetes mellitus & $3(3.4 \%)$ & $9(2.3 \%)$ & 0.349 & $0.55^{\neq}$ \\
\hline Preeclampsia & $1(1.1 \%)$ & $3(0.8 \%)$ & 0.114 & $0.56^{*}$ \\
\hline IUGR & $2(2.3 \%)$ & $3(0.8 \%)$ & 1.555 & $0.23^{*}$ \\
\hline Oligohydramnios & $1(1.1 \%)$ & $14(3.6 \%)$ & 1.434 & $0.33^{*}$ \\
\hline Polyhydramnios & $0(0 \%)$ & $3(0.8 \%)$ & 0.684 & $1.00^{*}$ \\
\hline Placental abruption & $0(0 \%)$ & $1(0.3 \%)$ & 0.227 & $1.00^{*}$ \\
\hline Postpartum hemorrhage & $5(5.7 \%)$ & $7(1.8 \%)$ & 4.399 & $0.04^{*}$ \\
\hline
\end{tabular}

\#: Pearson Chi-square test. ${ }^{*}$ Fisher exact test. 
between 1992 and 1998, researchers found that first deliveries in adolescents are not independently associated with an increased risk of adverse pregnancy outcome, but the seconds in these population are associated with an almost threefold risk of preterm delivery and stillbirth. We detected similar rates in terms of preterm birth ( $<32$ weeks), diabetes mellitus, preeclampsia, intrauterine growth restriction, oligohydramnios, polyhydramnios, and placental abruption in study groups which are matched for gravida, parity, and labor interval for two pregnancies. These findings may be explained by a good interaction with increased delivery number (except grand multiparity) and favorable pregnancy outcome.

Postpartum hemorrhage is an important cause for maternal mortality. There is no consensus for whether adolescent pregnancies have an increased risk for postpartum hemorrhage. In a retrospective cohort study including 15,892 adolescents (age $<19.9$ ) and 27,645 young adults (age 20-24.9) between 2002 and 2008, Kawakita et al. described that adolescents had increased risk of postpartum hemorrhage (adjusted odds ratio $=1.46 ; 95 \% \mathrm{CI}=1.10-1.95)(18)$. On the contrary, in the World Health Organization multi-country study, postpartum hemorrhage rate was similar in study groups. These rate was $0.8 \%$ at $<15$ years, $1.4 \%$ at $15-17$ years, $1.1 \%$ at $18-19$ years, and $1.2 \%$ at $20-24$ years $(\mathrm{p}=0.134)(19)$. We detected higher rates for postpartum hemorrhage both AP and control group, $5.7 \%$ and $1.8 \%$, respectively. Difference between both groups was statistically significant $(p=0.036)$.

In conclusion, adolescent multipara pregnancies were associated with higher risks of adverse pregnancy outcomes, in particular preterm birth, low birthweight, and postpartum hemorrhage. The other pregnancy complications and cesarean delivery rate were similar compared adult multiparas. But then, adolescent mothers should seek and receive adequate antenatal care by the appropriate multidisciplinary approach to minimize the risk for perinatal complication.

. Acknowledgements: This study presented at Perinatal Medicine 2017, organized by "Maternal Fetal Medicine and Perinatology Society of Turkey”, in Izmir, Turkey, April 28$29^{\text {th }} 2017$.

Declaration of Interest: The authors declare no conflicts of interest.

Funding: None.

\section{References}

1. World Health Organization. Adolescent pregnancy. World Health Organization 2014.

2. Chen XK, Wen SW, Fleming N, Demissie K, Rhoads GG, Walker M. Teenage pregnancy and adverse birth outcomes: a large population based retrospective cohort study. International journal of epidemiology. 2007 Apr;36(2):368-73. PubMed PMID: 17213208.
3. Conde-Agudelo A, Belizan JM, Lammers C. Maternalperinatal morbidity and mortality associated with adolescent pregnancy in Latin America: Cross-sectional study. American journal of obstetrics and gynecology. 2005 Feb;192(2):342-9. PubMed PMID: 15695970.

4. Jolly MC, Sebire N, Harris J, Robinson S, Regan L. Obstetric risks of pregnancy in women less than 18 years old. Obstetrics and gynecology. 2000 Dec;96(6):962-6. PubMed PMID: 11084186.

5. Malabarey OT, Balayla J, Klam SL, Shrim A, Abenhaim HA. Pregnancies in young adolescent mothers: a population-based study on 37 million births. Journal of pediatric and adolescent gynecology. 2012 Apr;25(2):98-102. PubMed PMID: 22088316.

6. Torvie AJ, Callegari LS, Schiff MA, Debiec KE. Labor and delivery outcomes among young adolescents. American journal of obstetrics and gynecology. 2015 Jul;213(1):95 e1-8. PubMed PMID: 25935776.

7. Schimmel MS, Bromiker R, Hammerman C, Chertman L, Ioscovich A, Granovsky-Grisaru S, et al. The effects of maternal age and parity on maternal and neonatal outcome. Archives of gynecology and obstetrics. 2015 Apr;291(4):793-8. PubMed PMID: 25227657.

8. Luke B, Brown MB. Elevated risks of pregnancy complications and adverse outcomes with increasing maternal age. Human reproduction. 2007 May;22(5):1264-72. PubMed PMID: 17289684.

9. de Vienne CM, Creveuil C, Dreyfus M. Does young maternal age increase the risk of adverse obstetric, fetal and neonatal outcomes: a cohort study. European journal of obstetrics, gynecology, and reproductive biology. 2009 Dec;147(2):151-6. PubMed PMID: 19733429.

10. Bai J, Wong FW, Bauman A, Mohsin M. Parity and pregnancy outcomes. American journal of obstetrics and gynecology. 2002 Feb;186(2):274-8. PubMed PMID: 11854649 .

11. Iacobelli S, Robillard PY, Gouyon JB, Hulsey TC, Barau G, Bonsante F. Obstetric and neonatal outcomes of adolescent primiparous singleton pregnancies: a cohort study in the South of Reunion Island, Indian Ocean. The journal of maternal-fetal \& neonatal medicine: the official journal of the European Association of Perinatal Medicine, the Federation of Asia and Oceania Perinatal Societies, the International Society of Perinatal Obstet. 2012 Dec;25 (12):2591-6. PubMed PMID: 22889253.

12. Suciu LM, Pasc AL, Cucerea M, Bell EF. Teenage Pregnancies: Risk Factors and Associated Neonatal Outcomes in an Eastern-European Academic Perinatal Care Center. American journal of perinatology 2015 Oct 20. PubMed PMID:26485250.

13. Zeck W, Wilkinson J, Obure J, Masenga G, Ulrich D, Oneko O. Comparison of obstetrical risk in adolescent primiparas at tertiary referral centres in Tanzania and Austria. The journal of maternal-fetal \& neonatal medi- 
cine: the official journal of the European Association of Perinatal Medicine, the Federation of Asia and Oceania Perinatal Societies, the International Society of Perinatal Obstet 2010 Dec;23(12):1470-4. PubMed PMID: 21067304.

14. Gupta N, Kiran U, Bhal K. Teenage pregnancies: obstetric characteristics and outcome. European journal of obstetrics, gynecology, and reproductive biology 2008 Apr;137 (2):165-71. PubMed PMID:17900787.

15. Geist RR, Beyth Y, Shashar D, Beller U, Samueloff A. Perinatal outcome of teenage pregnancies in a selected group of patients. Journal of pediatric and adolescent gynecology. 2006 Jun;19(3):189-93. PubMed PMID: 16731412

16. Jivraj S, Nazzal Z, Davies P, Selby K. Obstetric outcome of teenage pregnancies from 2002 to 2008: the Sheffield experience. Journal of obstetrics and gynaecology : the journal of the Institute of Obstetrics and Gynaecology.
2010 Apr;30(3):253-6. PubMed PMID: 20373925.

17. Timur H, Kokanali MK, Topcu HO, Topcu S, Erkilinc S, Uygur D, et al. Factors That Affect Perinatal Outcomes of the Second Pregnancy of Adolescents. Journal of pediatric and adolescent gynecology 2015 May;29 (1):18-21. PubMed PMID: 26428190.

18. Kawakita T, Wilson K, Grantz KL, Landy HJ, Huang CC, Gomez-Lobo V. Adverse Maternal and Neonatal Outcomes in Adolescent Pregnancy. Journal of pediatric and adolescent gynecology. 2016 Apr; 29(2): 130-6. PubMed PMID: 26327561.

19. Ganchimeg T, Ota E, Morisaki N, Laopaiboon M, Lumbiganon P, Zhang J, et al. Pregnancy and childbirth outcomes among adolescent mothers: a World Health Organization multicountry study. BJOG: an international journal of obstetrics and gynaecology 2014 Mar;121 Suppl 1:40-8. PubMed PMID: 24641534. 